\title{
EVALUASI KEANDALAN STRUKTUR GEDUNG KANTOR BUPATI SUMBAWA
}

\author{
BADARUDDIN ${ }^{1}$ \\ ${ }^{1}$ Dosen Proram Studi Teknik Sipil Fakultas Teknik dan Informatika Universitas Samawa
}

\begin{abstract}
The infrastructure development, especially the building, increase every year as each life sector also develops in national and regional level. Because of its importance function as of Sumbawa Regent Office as the community service center and the control center of Sumbawa Regency government, the building needs to have evaluation on the construction reliability to maintain its structural performance during the life time. The evaluation was started by collecting the secondary and primary data. The primary data was obtained by testing on the structural elements of column, beam, and floor slab using non-destructive. The results showed that $(T)$ the natural vibration period of building structure with Model Using Roof (MDA) is 0.291 second and frequency (f) $3.438 \mathrm{~Hz}$ while Model without Roof (MTA) is 0.308 second and frequency (f) $3.244 \mathrm{~Hz}$.

The value of deflection between floors (story drift) were in the safe limits, and the level stability of building (stability ratio) $\vartheta<0.1$, therefor the effect of P-Delta could be neglected. The maximum horizontal deflection at the building separation between the main and wing buildings is about 0.90 $\mathrm{cm}$ on the Model MDA and $3.10 \mathrm{~cm}$ on the Model MTA, while existing separation is $1.5 \mathrm{~cm}$. Accordingly, that building was categorized unsafe against impact when earthquake occurs on the Model MTA (SNI 03-1726-2012). The structure element strength of column, beam, and floor plate is in the safe condition.
\end{abstract}

Keywords: non-destructive, Performance ultimate limit, drift ratio.

\section{PENDAHULUAN}

Pembagunan infrastruktur, khususnya bangunan gedung tiap tahun meningkat seiring dengan berkembangnya tiap sektor kehidupan, baik di tingkat pusat maupun di daerah. Bangunan gedung adalah wujud fisik hasil pekerjaan konstruksi yang menyatu dengan tempat kedudukannya, sebagian atau seluruhnya berada di atas dan/atau di dalam tanah dan/atau air, yang berfungsi sebagai tempat manusia melakukan kegiatannya, baik untuk hunian atau tempat tinggal, kegiatan keagamaan, kegiatan usaha, kegiatan sosial, budaya maupun kegiatan khusus (Undangundang RI No. 28 Tahun 2002).

Mengingat pentingnya fungsi bangunan gedung dalam hal ini bangunan gedung kantor Bupati Sumbawa sebagai pusat pelayanan masyarakat dan pusat pengendalian pemerintah Kabupaten Sumbawa, maka perlu kepastian keandalan bangunan tersebut, sehingga bisa beroperasi sesuai dengan fungsinya selama umur rencana.

Bangunan gedung Kantor Bupati Sumbawa Nusa Tenggara Barat dibangun pada tahun 2005, terdiri dari 3 (tiga). Dalam masa layannya bangunan tersebut telah mengalami beberapa kerusakan kecil pada lantai dan retak pada delatasi, Foto existing dapat dilihat pada Gambar 1.1 dan Gambar 1.2. Guna mempertahankan kinerja dari bangunan tersebut sesuai dengan perencanaannya, maka perlu dilakukan evaluasi agar dapat diketahui kelayakan dan keamanan dari bangunan tersebut. 


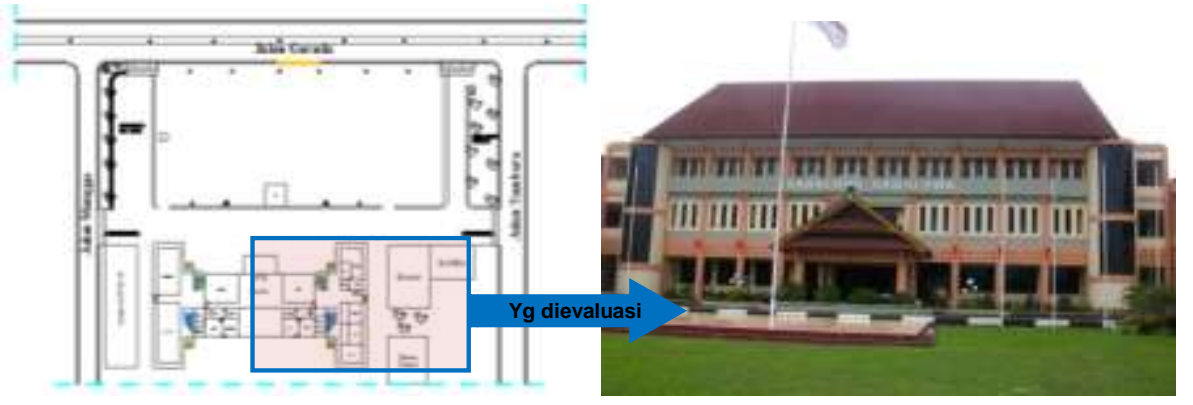

Gambar 1 Lokasi pengujian Kantor Bupati Sumbawa
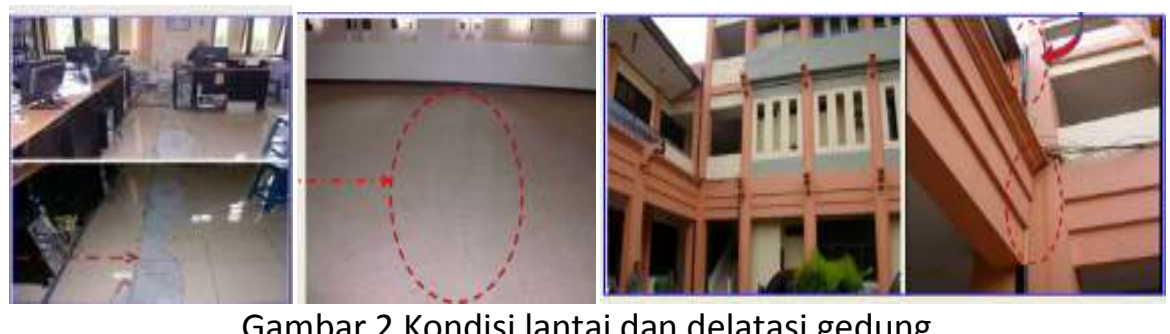

Gambar 2 Kondisi lantai dan delatasi gedung

Penelitian bertujuan untuk melakukan pendataan kualitas bahan, kondisi kerusakan gedung dan pengukuran dimensi komponen struktur, guna mengetahui keandalan struktur bangunan khususnya persyaratan keamanan bangunan gedung Kantor Bupati Sumbawa.

Adapun ruang lingkup penelitian dibatasi sesuai dengan uraian di bawah ini:

1. Penelitian dilakukan pada bangunan utama gedung kantor Bupati Sumbawa.

2. Pengujian bahan pada struktur utama dilakukan dengan metode tidak merusak (non-destructive test), menggunakan Hammer Test dan UPV.

3. Data bahan dan dimensi komponen struktur mengacu pada as built drawing dan Rencana Kerja dan Syarat-syarat (RKS).

4. Pemodelan struktur menggunakan program SAP 2000 V.11.

5. Pembebanan gedung SNI 03-1727-1989 dan SNI 03-1726-2012.

6. Peta wilayah gempa mengacu pada Peta Hazard Gempa Indonesia 2010.

7. Analisis kapasitas elemen struktur dihitung berdasarkan SNI 03-2847-2002, menggunakan Program Response 2000 dan Shell 2000.

8. Bagian struktur yang dievaluasi adalah struktur bangunan bagian atas, sedangkan struktur bangunan bawah yaitu fondasi dan interaksi struktur dengan tanah tidak ditinjau.

\section{LANDASAN TEORI}

\section{Keandalan Bangunan Gedung}

Menurut Undang-Undang RI Nomor 28 Tahun 2002, keandalan bangunan gedung harus memenuhi persyaratan keselamatan, kesehatan, kenyamanan dan kemudahan. Persyaratan keselamatan yaitu kemampuan struktur bangunan gedung yang stabil dan kukuh dalam mendukung beban muatan merupakan kemampuan struktur bangunan gedung yang stabil dan kukuh sampai dengan kondisi pembebanan maksimum dalam mendukung beban muatan hidup dan beban muatan mati, serta untuk daerah/zona tertentu kemampuan untuk mendukung beban muatan yang timbul akibat perilaku alam.

\section{Analisis dinamik}

Dalam analisis dinamik struktur melibatkan dimensi gaya, panjang dan waktu. Dalam hal ini magnitudo beban, arah beban atau posisi beban yang bekerja, maupun kombinasi dari ketiganya dapat merupakan fungsi waktu sehingga respon struktur merupakan fungsi waktu (Suhendro, 2000).

1). Beban dinamik

Beban dinamik adalah beban yang besarnya, arahnya atau posisinya, maupun kombinasi dari ketiganya berubah-ubah menurut fungsi waktu, sehingga respon struktur yang meliputi tegangan, regangan, displacement, dan reaksi pada tumpuan juga 
merupakan fungsi waktu atau bersifat dinamik (Suhendro, 2000).

Ditinjau dari karakteristik beban dinamiknya, analisis dinamik dapat dikategorikan menjadi (Suhendro, 2000):

a. Analisis deterministik, apabila beban dinamiknya dapat didefinisikan secara baik, seperti pada beban mesin. Hasil analisis deterministik akan memberikan hasil berupa respon struktur (displacement, gayagaya internal, tegangan dan regangan dan reaksi tumpuan).

b. Analisis non-determinstik, apabila beban dinamiknya tidak didefinisikan secara baik, seperti pada beban gempa dan beban angin. Hasil analisis non-deterministik akan memberikan hasil berupa respon struktur secara probablistik karena beban dinamiknya sendiri memang tidak terdefinisikan dengan baik.

2). Karakteristik analisis dinamik

Karakteristik analisis dinamik adalah (Suhendro, 2000):

a. Beban merupakan fungsi waktu, $\mathrm{P}(\mathrm{t})$ dan respons struktur yaitu tegangan, regangan, perpindahan, reaksi merupakan fungsi waktu, solusi tidak hanya satu, sehingga struktur dianalisis pada kondisi pengaruh paling buruk.

b. Adanya gaya inersia (inertia force) yang harus diperhitungkan dalam persamaan keseimbangan.

3). Sistem berderajat kebabasan banyak (Multy Degree of Freedom atau MDOF), (lihat Gambar 3)

Pada struktur bangunan bertingkat memiliki derajat kebebasan banyak (MDOF), dimana anggapan seperti shear building. Dengan demikian, maka jumlah derajat kebebasan menjadi sebanyak jumlah lantai. Widodo (2000), prinsip shear building apabila suatu struktur bangunan bertingkat banyak bergoyang ke arah horisontal, maka umumnya terdapat 3 macam pola goyangan yang terjadi (lihat Gambar 4):

a. Pola goyangan pertama adalah bangunan bergoyang dengan dominasi geser (shear mode) atau pola goyangan geser. b. Pola goyangan kedua adalah pola goyangan bangunan yang didominasi oleh lentur (flexural mode).

c. Pola goyangan ketiga adalah kombinasi pola goyangan geser dan lentur.

Pada analisis dinamika struktur pola goyangan pertamalah yang umumnya diadopsi, karena struktur dianggap cukup fleksibel dengan lantai-lantai tingkat yang relatif kaku, dengan beberapa anggapan sebagai berikut:

a. Massa struktur terkonsentrasi pada tiap lantai tingkat.

b. Lantai-lantai tingkat sangat kaku dibanding dengan kolom-kolomnya karena balokbalok portal disatukan secara monolit oleh pelat lantai.

c. Simpangan massa tidak dipengaruhi oleh beban aksial kolom atau deformasi aksial kolom diabaikan.

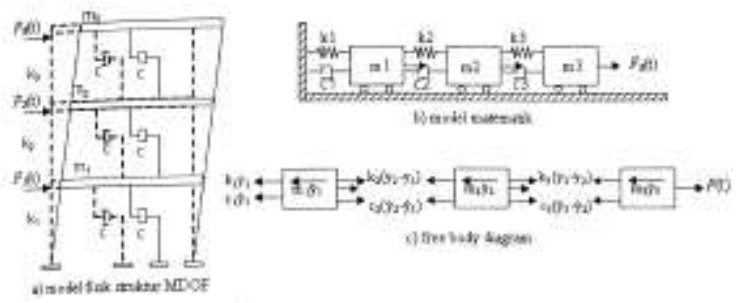

Gambar 3 Struktur MDOF akibat gerakan struktur (Widodo, 2000).

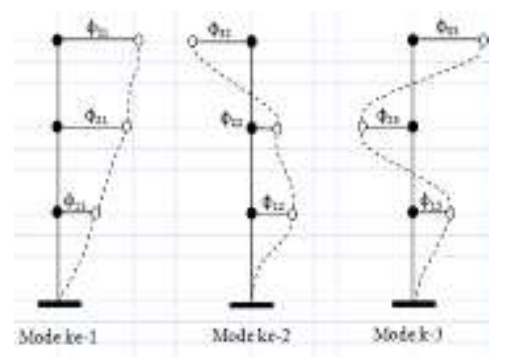

Gambar 4 Normal modes struktur tiga tingkat (Widodo, 2000)

\section{Tingkat Kinerja Struktur Gedung}

Menurut beberapa standar, kinerja struktur gedung dapat dikategorikan:

1. Tingkat kinerja struktur gedung menurut FEMA 451

\section{Berdasarkan NEHRP (National}

Earthquake Hazard Reduction Program) FEMA 451, kinerja suatu bangunan dibagi menjadi empat tingkat, yaitu operational, immediate occupancy, life safety dan collapse prevention. 
2. Tingkat kinerja struktur gedung menurut SNI 03-1726-2002

Simpangan antar lantai ditentukan berdasarkan dua kinerja, yaitu kinerja batas layan dan kinerja batas ultimit.

3. Tingkat kinerja struktur gedung menurut RSNI 03-1726-2012

Simpangan antar lantai ditentukan hanya berdasarkan satu kinerja, yaitu kinerja batas ultimit, yang ditentukan oleh simpangan antar tingkat maksimum akibat pengaruh gempa rencana dalam kondisi gedung di ambang keruntuhan, sehingga dapat membatasi kemungkinan terjadinya keruntuhan struktur gedung yang dapat menimbulkan korban jiwa manusia dan untuk mencegah benturan berbahaya antargedung atau antarbagian struktur gedung yang dipisah dengan sela pemisah (sela dilatasi).

Syarat kinerja batas ultimit berdasar RSNI 03-1726-2012 adalah penentuan simpangan antarlantai tingkat desain $(\Delta)$ harus dihitung sebagai perbedaan defleksi pada pusat massa di tingkat teratas dan terbawah yang ditinjau.

a. Simpangan antar lantai. Simpangan antar lantai (story drift) dihitung berdasarkan data hasil analisis pada struktur. Deformasi struktur pada Level $\mathrm{x}$ :

$\delta_{\mathrm{x}}=\frac{\mathrm{C}_{\mathrm{d}} \delta_{\mathrm{xe}}}{\mathrm{I}_{\mathrm{e}}}$

dimana:

$\mathrm{C}_{\mathrm{d}} \quad$ : Faktor pembesaran defleksi

$\delta_{\mathrm{xe}} \quad$ : Defleksi yang ditentukan oleh analisis

$\mathrm{I}_{\mathrm{e}} \quad$ elastis

: Faktor keutamaan

b. Pengaruh P-Delta. Dalam perencanaan bangunan tinggi, pergerakan lateral kolom akibat pengaruh beban aksial $\mathrm{P}$ dan horizontal displacement akan menimbulkan momen sekunder pada balok dan kolom, serta tambahan story drift. Stabilitas dari sistem struktur akibat pengaruh P-delta setiap tingkat dihitung:

$\theta=\frac{\mathrm{P}_{\mathrm{x}} \Delta \mathrm{I}_{\mathrm{e}}}{\mathrm{V}_{\mathrm{x}} \mathrm{h}_{\mathrm{sx}} \mathrm{C}_{\mathrm{d}}}$ di mana:

$\mathrm{P}_{\mathrm{x}} \quad$ : Beban desain vertikal total pada tingkat di atas level $x$

$\Delta \quad$ : Drift tingkat (simpangan antar lantai) yang dihitung pada level desain $\mathrm{I}_{\mathrm{e}} \quad$ (termasuk $\left.\mathrm{C}_{\mathrm{d}}\right)$

\section{: Faktor keutamaan}

$\mathrm{V}_{\mathrm{x}} \quad$ : Gaya geser seismik total tingkat yang ditinjau

$\mathrm{H} \quad$ : Tinggi antar tingkat yang ditinjau

$\mathrm{C}_{\mathrm{d}}$ : Faktor pembesaran defleksi dalam Tabel 9 (RSNI 03-1726-2012)

Jika $\theta<0,1$, pengaruh $\mathrm{P}$-delta dapat diabaikan.

c. Separasi antar gedung. Separasi pada umumnya dibutuhkan untuk melindungi atau mereduksi kemungkinan terjadinya benturan pada struktur-struktur yang berdampingan.

Separasi dalam gedung yang sama peraturan mensyaratkan suatu jarak pemisah sebesar ठMT.

$\delta_{\mathrm{MT}}=\delta_{\mathrm{M} 1}+\delta_{\mathrm{M} 2}$

(3)

dimana:

$\delta_{\mathrm{M} 1}$ : displacement inelastik maksimum dari struktur-1

$\delta_{\mathrm{M} 2}$ : displacement inelastik maksimum dari struktur-2

$\delta_{M}=\left(\delta_{x}\right) \max =\frac{C_{d} \delta_{21}}{I_{e}}$

Untuk menentukan separasi minimum dari expansion joint, maka untuk setiap struktur perlu ditentukan displacement inelastik maksimum lantai $\delta x$.

\section{METODOLOGI PENELITIAN}

a. Penelitian secara fisik

Penelitian dilakukan dengan observasi, identifikasi kondisi bangunan dan pendataan pada struktur gedung menggunakan metode pengujian tidak merusak (non-destructive test). Adapu alat-alat yang digunakan adalah Microcrack Meter, Rebar Locator, Schmidt Rebound Hammer Test, Ultrasonic Pulse Velocity (UPV) Test. 
b. Penelitian secara hipotetik dan analitik

Penelitian dilakukan guna mendapatkan hubungan antara variabel-variabel yang saling berpengaruh, menganalisis data, pembahasan masalah dan kesimpulan.

\section{PEMODELAN STRUKTUR GEDUNG}

Pemodelan struktur gedung Kantor Bupati Sumbawa mengacu pada kondisi existing dan gambar as build drawing. Kondisi site plan bangunan Kantor Bupati Sumbawa terdiri dari 1 gedung bangunan induk 3 lantai yang mempunyai tinggi $12,50 \mathrm{~m}$ dari muka tanah dan 2 gedung bangunan sayap masingmasing 2 lantai yang mempunyai tinggi 8,50 m dari muka tanah.

\section{Pemodelan struktur dengan software SAP2000}

Pemodelan struktur gedung dalam evaluasi ini menggunakan Program SAP 2000, utamanya bangunan induk sedangkan untuk bangunan sayap dibuat model hanya untuk mengetahui simpangan struktur yang berkaitan dengan separasi antar gedung. Dalam hal ini model struktur dibuat 2 macam model yaitu Model dengan Atap (MDA) dan Model dengan Atap (MTA). Pada Model dengan Atap, dianalisis portal menyatu dengan atap dan pada Model tanpa Atap, struktur portal dianalisis terpisah dengan struktur atap.

\section{a. Pemodelan rangka atap}

Pemodelan rangka atap model truss bertujuan untuk mendapatkan nilai reaksi tumpuan yang diinput sebagai beban titik pada MTA. Spesifikasi pada pemodelan rangka atap dapat dilihat pada Tabel 1.

Tabel 1 Spesifikasi pada pemodelan rangka atap

\begin{tabular}{|c|c|c|}
\hline No & Uraian & Keterangan \\
\hline 1. & $\begin{array}{l}\text { Material kuda-kuda: } \\
\text { - Bangunan induk } \\
\text { - Bangunan sayap }\end{array}$ & 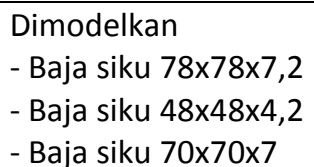 \\
\hline 2. & $\begin{array}{l}\text { Material penutup } \\
\text { atap: } \\
\text { - Genteng } \\
\text { - Usuk dan reng }\end{array}$ & Tidak dimodelkan \\
\hline 3. & Pembebanan & $\begin{array}{l}\text {-Beban mati dari atap } \\
\text {-Beban hidup } \\
\text { - Beban angin }\end{array}$ \\
\hline
\end{tabular}

\begin{tabular}{|c|l|l|}
\hline & & - Beban gempa \\
\hline 4. & $\begin{array}{l}\text { Pedoman } \\
\text { pembebanan }\end{array}$ & $\begin{array}{l}\text { PPPURG 1987 } \\
\text { RSNI-03-1726-2012 }\end{array}$ \\
\hline 5. & Tumpuan kuda-kuda & Sendi-sendi \\
\hline
\end{tabular}
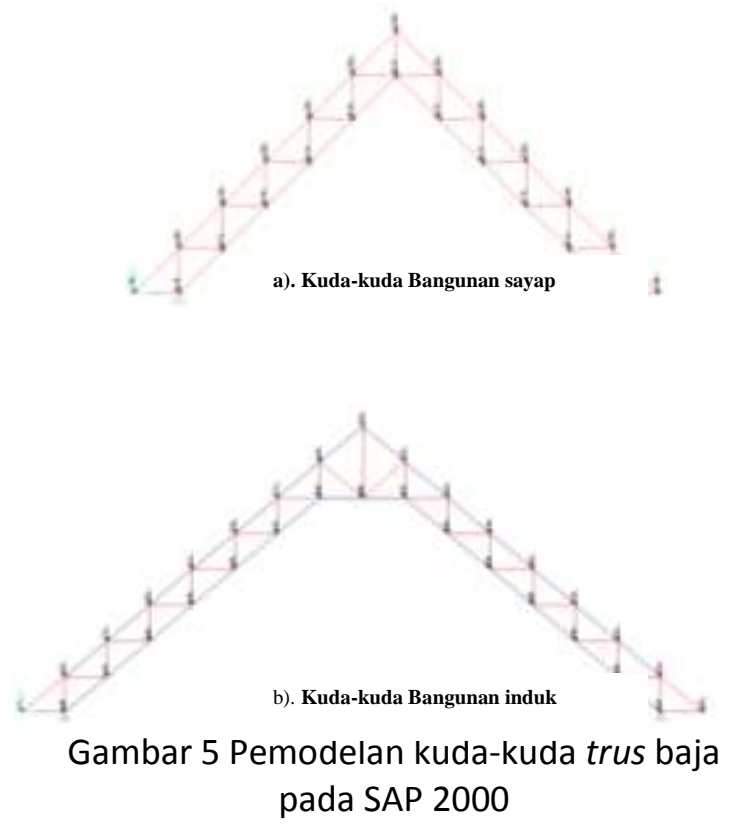

b. Pemodelan struktur gedung

Pemodelan struktur gedung dibuat 2 model yaitu MDA dan MTA. Adapun sistem tumpuan kolom ke pondasi diasumsikan sebagai tumpuan sendi, karena bangunan dibangun di atas tanah sedang, jenis pondasi dangkal/pondasi setempat dan rasio kekakuan balok sloof dengan kolom relatif kecil (kb/kc kurang dari 1). Struktur gedung dalam evaluasi ini dibuat dalam 2 kondisi, struktur ditinjau pada kondisi sebelum retak dan kondisi retak (Budiono dan Supriatna, 2011) yaitu:

a. Model struktur gedung sebelum retak (crack), untuk mendapatkan nilai periode fundamental $(T)$, selanjutnya digunakan untuk menghitung gaya geser dasar (base shear) bangunan akibat gempa.

b. Model struktur gedung dalam kondisi retak (crack section), untuk perhitungan kekuatan gaya-gaya dalam dan simpangan pada struktur. Spesifikasi pada pemodelan struktur gedung dapat dilihat pada Tabel 2 . 
Tabel 2 Spesifikasi pada pemodelan struktur gedung

\begin{tabular}{|c|c|c|c|}
\hline \multirow[b]{2}{*}{ No } & \multirow[b]{2}{*}{ Uraian } & \multicolumn{2}{|c|}{ Keterangan } \\
\hline & & $\begin{array}{c}\text { Model } \\
\text { dengan Atap }\end{array}$ & $\begin{array}{c}\text { Model tanpa } \\
\text { Atap (MTA) }\end{array}$ \\
\hline 1. & $\begin{array}{l}\text { Material kuda- } \\
\text { kuda } \\
\text { - Bangunan induk } \\
\text { - Bangunan sayap }\end{array}$ & $\begin{array}{l}\text { Dimodelkan } \\
\text { - Baja siku } \\
78 \times 78 \times 7,2 \\
\text { - Baja siku } \\
48 \times 48 \times 4,2 \\
\text { - Baja siku } \\
70 \times 70 \times 7\end{array}$ & $\begin{array}{l}\text { Tidak } \\
\text { dimodelkan }\end{array}$ \\
\hline 2. & $\begin{array}{l}\text { Material penutup } \\
\text { atap: } \\
\text { Genteng dan usuk } \\
\text { dan reng }\end{array}$ & Dimodelkan & $\begin{array}{l}\text { Tidak } \\
\text { dimodelkan }\end{array}$ \\
\hline 3. & $\begin{array}{l}\text { Struktur: } \\
\text { Kolom beton, } \\
\text { balok beton, pelat } \\
\text { lantai beton, } \\
\text { dinding bata }\end{array}$ & Dimodelkan & Dimodelkan \\
\hline 4. & Pondasi & $\begin{array}{l}\text { Tidak } \\
\text { dimodelkan }\end{array}$ & $\begin{array}{l}\text { Tidak } \\
\text { dimodelkan }\end{array}$ \\
\hline 5. & $\begin{array}{l}\text { Non struktur: } \\
\text { Dinding partisi, } \\
\text { kusen pintu \& } \\
\text { jendela dan } \\
\text { plafon }\end{array}$ & $\begin{array}{l}\text { Tidak } \\
\text { dimodelkan }\end{array}$ & $\begin{array}{l}\text { Tidak } \\
\text { dimodelkan }\end{array}$ \\
\hline 6. & Pembebanan & $\begin{array}{l}\text { - Beban mati } \\
\text { - Beban } \\
\text { hidup } \\
\text { - Beban } \\
\text { angin } \\
\text { - Beban } \\
\text { gempa }\end{array}$ & $\begin{array}{l}\text { - Beban mati } \\
\text { - Beban hidup } \\
\text { - Beban angin } \\
\text { - Beban } \\
\text { gempa }\end{array}$ \\
\hline 7. & $\begin{array}{l}\text { Pedoman } \\
\text { pembebanan }\end{array}$ & $\begin{array}{l}\text { PPPURG } \\
1987 \\
\text { RSNI-03- } \\
1726-2012 \\
\end{array}$ & $\begin{array}{l}\text { PPPURG } 1987 \\
\text { RSNI-03-1726- } \\
2012\end{array}$ \\
\hline 8. & Tumpuan kolom & Sendi & Sendi \\
\hline
\end{tabular}

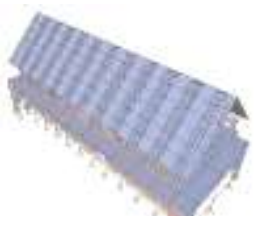

a). Bangunan sayap

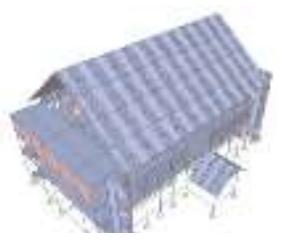

b). Bangunan induk
Gambar 6 Pemodelan struktur MDA pada SAP 2000

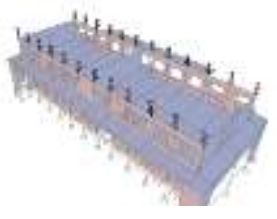

a). Bangunan sayap

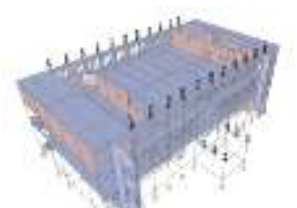

b). Bangunan induk
Gambar 7 Pemodelan struktur MTA pada SAP 2000

2. Pemodelan elemen struktur pada Response-2000 dan Shell-2000

Penggunaan program Response-2000 dalam evaluasi ini adalah untuk mengetahui besarnya gaya-gaya dalam yang bekerja pada penampang balok dan kolom yang mencerminkan kekuatan kapasitas penampang tersebut. Program Shell-2000 digunakan untuk menganalisis besarnya gaya-gaya dalam yang bekerja pada pelat lantai. Model dibuat dengan memasukkan dimensi penampang, jumlah dan ukuran tulangan, mutu bahan sesuai dengan data-data elemen struktur existing dan as build drawing.

\section{HASIL DAN PEMBAHASAN}

a. Hasil Evaluasi Bahan Elemen Struktur

1. Kuat tekan beton

Kuat tekan beton elemen struktur diperoleh setelah dilakukan uji statistik dengan metode distribusi normal terhadap data hasil uji Hammer Test. Hasil pengujian kuat tekan beton adalah sebagai berikut:
a) Elemen struktur kolom
$: f^{\prime} c=11$ $\mathrm{MPa}$
b) Elemen struktur balok$$
: f^{\prime} c=24
$$ $\mathrm{MPa}$
c) Elemen struktur pelat lantai $\quad: f^{\prime} c=40$ MPa.

Perbedaan mutu kuat tekan beton dari ketiga elemen tersebut bisa terjadi karena pada saat pemilihan material beton tidak dilakukan uji material dengan teliti, pencampuran/pengadukan beton dilakukan dengan cara manual dengan tenaga manusia serta pengecoran yang tidak sempurna.

2. Tegangan leleh baja tulangan

Tegangan leleh baja tulangan ditentukan berdasarkan pada data yang 
tercantum dalam Rencana Kerja dan Syaratsyarat (RKS) yaitu disebutkan sebagai berikut:

a. Tulangan struktur diameter $12 \mathrm{~mm}$ ke atas menggunakan baja tulangan ulir U32 (PBI'71) setara dengan $\mathrm{fy}=272,625 \mathrm{MPa}$.

b. Tulangan struktur diameter di bawah diameter $12 \mathrm{~mm}$ menggunakan baja tulangan polos U24 (PBI'71) setara dengan $f y=203,978 \mathrm{MPa}$.

\section{b. Hasil Evaluasi Kinerja Struktur Gedung}

Evaluasi kinerja struktur diperoleh dengan membanding hasil analisis Model dengan Atap dan Model tanpa Atap menggunakan software SAP 2000 yang terdiri dari:

Tabel 3 Perhitungan story drift kinerja batas ultimit arah (U-S)

\begin{tabular}{|c|c|c|c|c|c|c|c|c|}
\hline \multirow{3}{*}{ Lantai } & \multicolumn{3}{|c|}{ Moden dengan Atap } & \multicolumn{3}{c|}{ Model tanpa Atap } & \multicolumn{2}{c|}{ Cek Syarat } \\
\cline { 2 - 9 } & $\begin{array}{c}\text { Total } \\
\text { Drift }\end{array}$ & $\begin{array}{c}\text { Perpin } \\
\text { dahan }\end{array}$ & $\begin{array}{c}\text { Story } \\
\text { Drift }\end{array}$ & $\begin{array}{c}\text { Total } \\
\text { Drift }\end{array}$ & $\begin{array}{c}\text { Perpin } \\
\text { dahan }\end{array}$ & $\begin{array}{c}\text { Story } \\
\text { Drift }\end{array}$ & $\begin{array}{c}\text { Story } \\
\text { Drift Izin }\end{array}$ & $\begin{array}{c}\text { Story } \\
\text { Drift }<\end{array}$ \\
\hline Atap & 9,406 & 6,265 & 15,663 & 5,077 & 1,415 & 3,538 & 80,00 & OK \\
\hline Lantai & 3,141 & 0,288 & 0,720 & 3,662 & 0,527 & 1,318 & 80,00 & OK \\
\hline Lantai & 2,853 & 2,853 & 7,133 & 3,136 & 3,135 & 7,838 & 90,00 & OK \\
\hline
\end{tabular}

Tabel 4 Perhitungan story drift kinerja batas ultimit arah (B-T)

\begin{tabular}{|c|c|c|c|c|c|c|c|c|}
\hline \multirow{3}{*}{ Lantai } & \multicolumn{3}{|c|}{ Moden dengan Atap } & \multicolumn{3}{c|}{ Model tanpa Atap } & \multicolumn{2}{c|}{ Cek Syarat } \\
\cline { 2 - 9 } & $\begin{array}{c}\text { Total } \\
\text { Drift }\end{array}$ & $\begin{array}{c}\text { Perpin } \\
\text { dahan }\end{array}$ & $\begin{array}{c}\text { Story } \\
\text { Drift }\end{array}$ & $\begin{array}{c}\text { Total } \\
\text { Drift }\end{array}$ & $\begin{array}{c}\text { Perpin } \\
\text { dahan }\end{array}$ & $\begin{array}{c}\text { Story } \\
\text { Drift }\end{array}$ & $\begin{array}{c}\text { Story } \\
\text { Drift Izin }\end{array}$ & $\begin{array}{c}\text { Story } \\
\text { Drift }<\end{array}$ \\
\hline Atap & 7,142 & 5,012 & 12,53 & 18,417 & 16,041 & 40,103 & 80,00 & OK \\
\hline Lantai & 2,13 & 0,94 & 2,35 & 2,376 & 0,961 & 2,403 & 80,00 & OK \\
\hline Lantai & 1,19 & 1,19 & 2,975 & 1,415 & 1,415 & 3,538 & 90,00 & OK \\
\hline
\end{tabular}

Dari hasil perhitungan dapat disimpulkan bahwa simpangan antarlantai (story drift) kinerja batas ultimit Model dengan Atap dan Model tanpa Atap arah (U-S) dan arah (B-T) yang terjadi pada setiap lantai struktur gedung tersebut masih lebih kecil dari
1. Hasil perhitungan simpangan antar lantai (story drift)

Simpangan antar lantai (story drift) dihitung berdasarkan data hasil analisis pada struktur yang terdiri dari nilai:

- Total drift : nilai diperoleh dari hasil analisis SAP2000.

- Perpindahan: selisih total drift pada lantai $x$ dengan lantai di atasnya

- Story Drift : dihitung dengan menggunakan Persamaan (1).

Hasil perhitungan story drift kinerja batas ultimit arah (U-S) dan arah (B-T) dapat dilihat pada Tabel 3 dan Tabel 4. 
Tabel 6 Perhitungan P-Delta arah (B-T)

\begin{tabular}{|c|c|c|c|c|c|c|c|c|}
\hline \multirow[b]{2}{*}{ Lantai } & \multicolumn{3}{|c|}{ Beban pada Struktur } & \multicolumn{2}{|c|}{$\begin{array}{c}\text { Model dengan } \\
\text { Atap }\end{array}$} & \multicolumn{2}{|c|}{$\begin{array}{c}\text { Model tanpa } \\
\text { Atap }\end{array}$} & \multirow[b]{2}{*}{ Cek } \\
\hline & $\begin{array}{l}\text { Gaya } \\
\text { Geser } \\
\text { Seismi }\end{array}$ & $\begin{array}{c}\text { Beban } \\
\text { Vertikal } \\
\text { Total(kN }\end{array}$ & $\begin{array}{c}\text { Beban } \\
\text { Vertikal } \\
\text { Kumulatif }\end{array}$ & $\begin{array}{l}\text { Story } \\
\text { Drift } \\
\text { (m) }\end{array}$ & $\begin{array}{c}\text { Stability } \\
\text { Ratio } \\
(\theta)\end{array}$ & $\begin{array}{l}\text { Story } \\
\text { Drift } \\
\text { (m) }\end{array}$ & $\begin{array}{c}\text { Stability } \\
\text { Ratio } \\
(\theta)\end{array}$ & \\
\hline Atap & 138,90 & 2954,02 & 2954,029 & 0,013 & 0,027 & 0,04 & 0,035 & OK \\
\hline Lantai & 443,91 & & & 0,002 & & 0,00 & & OK \\
\hline Lantai & 595,18 & 8936,00 & 21428,87 & 0,003 & 0,006 & 0,00 & 0,003 & OK \\
\hline
\end{tabular}

Berdasarkan hasil perhitungan stability ratio $(\theta)$, dapat disimpulkan bahwa struktur gedung Model dengan Atap dan Model tanpa Atap tersebut pada masing-masing arah (U-S) dan arah (B-T) pengaruh P-Delta dapat diabaikan, karena nilai stability ratio yang terjadi pada semua lantai kurang dari 0,1 sesuai ketentuan yang disyaratkan oleh RSNI 03-1726-2012.

\section{Separasi antar gedung}

Kantor Bapati Sumbawa terdiri dari 3 bangunan gedung yaitu 1 gedung bangunan induk dan 2 gedung bangunan sayap seperti diilustrasikan pada Gambar 8. Separasi antar gedung perlu dicek agar dapat diketahui keamanan gedung tersebut terhadap tumbukan pada arah (U-S).
Dalam hal ini yang ditinjau hanya pada ketinggian lantai 3 bangunan induk dan pada ketinggian atap (ring balok) bangunan sayap (elevasi 8,50 m) Model dengan Atap dan Model tanpa Atap.

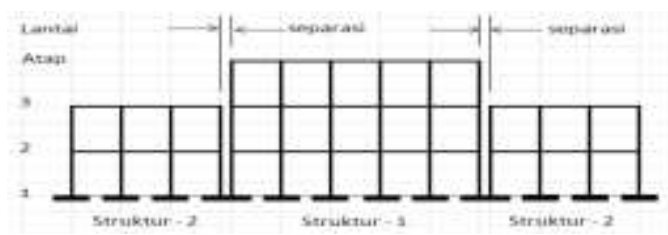

Gambar 8 Sket Separasi struktur bangunan gedung Kantor Bupati Sumbawa

a. Defleksi maksimum struktur-1

Perhitungan tersebut ditinjau lantai 3 pada struktur-1 $=$ ketinggian dak pada struktur2. Lihat Tabel 7 dan Tabel 8.

Tabel 7 Perhitungan defleksi maksimum arah (U-S) struktur-1

\begin{tabular}{|c|c|c|c|c|c|c|c|c|}
\hline \multirow{2}{*}{ Lantai } & \multicolumn{3}{|c|}{ Moden dengan Atap } & \multicolumn{3}{c|}{ Model tanpa Atap } & \multicolumn{2}{c|}{ Cek Syarat } \\
\cline { 2 - 9 } & $\begin{array}{c}\text { Total } \\
\text { Drift }\end{array}$ & $\begin{array}{c}\text { Perpin } \\
\text { dahan }\end{array}$ & $\begin{array}{c}\text { Defleksi } \\
\text { max }(\delta\end{array}$ & $\begin{array}{c}\text { Total } \\
\text { Drift }\end{array}$ & $\begin{array}{c}\text { Perpin } \\
\text { dahan }\end{array}$ & $\begin{array}{c}\text { Deflek } \\
\text { si max }\end{array}$ & $\begin{array}{c}\text { Story } \\
\text { Drift Izin }\end{array}$ & $\begin{array}{c}\text { Story } \\
\text { Drift }<\end{array}$ \\
\hline Atap & 9,406 & 6,265 & 15,663 & 5,077 & 1,415 & 3,538 & 80,00 & OK \\
\hline Lantai & 3,141 & 0,288 & 0,720 & 3,662 & 0,527 & 1,318 & 80,00 & OK \\
\hline Lantai & 2,853 & 2,853 & 7,133 & 3,135 & 3,135 & 7,838 & 90,00 & OK \\
\hline
\end{tabular}

b. Defleksi maksimum struktur-2

Tabel 8 Perhitungan defleksi maksimum arah (U-S) struktur-2

\begin{tabular}{|c|c|c|c|c|c|c|c|c|}
\hline \multirow{3}{*}{ Lantai } & \multicolumn{3}{|c|}{ Moden dengan Atap } & \multicolumn{3}{c|}{ Model tanpa Atap } & \multicolumn{2}{c|}{ Cek Syarat } \\
\cline { 2 - 10 } & $\begin{array}{c}\text { Total } \\
\text { Drift }\end{array}$ & $\begin{array}{c}\text { Perpin } \\
\text { dahan }\end{array}$ & $\begin{array}{c}\text { Defleksi } \\
\text { max }(\delta\end{array}$ & $\begin{array}{c}\text { Total } \\
\text { Drift }\end{array}$ & $\begin{array}{c}\text { Perpin } \\
\text { dahan }\end{array}$ & $\begin{array}{c}\text { Deflek } \\
\text { si max }\end{array}$ & $\begin{array}{c}\text { Story } \\
\text { Drift Izin }\end{array}$ & $\begin{array}{c}\text { Story } \\
\text { Drift }<\end{array}$ \\
\hline Atap & 4,145 & 2,977 & 7,443 & 12,723 & 11,704 & 29,260 & 80,00 & OK \\
\hline Lantai & 1,168 & 1,168 & 2,920 & 1,019 & 1,019 & 2,548 & 90,00 & OK \\
\hline
\end{tabular}


c. Defleksi maksimum total (סMT)

Defleksi maksimum total, ditentukan dengan menjumlah defleksi maksimum struktur-1 dengan defleksi maksimum struktur-

2. Lihat Tabel 9.

Tabel. 9 Perhitungan separasi antar gedung arah (U-S)

\begin{tabular}{|c|c|}
\hline Model dengan Atap & Model tanpa Atap \\
\hline $\begin{aligned} \delta M T & =\delta M 1+\delta M 2 \\
& =0,720+7,443 \mathrm{~mm} \\
& =0,90 \mathrm{~cm}\end{aligned}$ & $\begin{aligned} \delta M T & =\delta M 1+\delta M 2 \\
& =, 318+29,260 \mathrm{~mm} \\
& =3,10 \mathrm{~cm}\end{aligned}$ \\
\hline
\end{tabular}

Dari hasil perhitungan separasi gedung (building sparation) antara gedung induk dan gedung sayap, dapat disimpulkan bahwa gedung tersebut Model dengan Atap aman.
Sedangkan Model tanpa Atap tidak aman terhadap tumbukan pada saat terjadinya gempa karena defleksi maksimum total yang terjadi adalah sebesar $3,10 \mathrm{~cm}$ lebih besar dari separasi existing yaitu $1,5 \mathrm{~cm}$.

\section{c. Hasil analisis kekuatan elemen struktur}

Kekuatan elemen struktur kolom dan balok dapat dianalisis menggunakan bantuan program Response-2000, sedangkan untuk elemen pelat lantai dianalisis dengan bantuan program Shell 2000.

1. Kekuatan elemen kolom.

Perhitungan kekuatan elemen kolom disajikan pada Tabel 10.

Tabel 10 Perbandingan (Mr) dengan (Mu), (Nu) dengan ( $\mathrm{Nr}$ ) dan $(\mathrm{Vu})$ dengan $(\mathrm{Vr})$ Kolom

\begin{tabular}{|c|c|c|c|c|c|c|c|c|}
\hline \multirow{2}{*}{ Lantai } & \multirow{2}{*}{$\begin{array}{l}\text { Dimensi } \\
\text { Kolom } \\
(\mathrm{cm})\end{array}$} & \multicolumn{2}{|c|}{ Momen (kN.m) } & \multicolumn{2}{|c|}{ Gaya Aksial (N) (kN) } & \multicolumn{2}{|c|}{ Gaya Geser (V) (kN) } & \multirow{2}{*}{$\begin{array}{c}\text { Cek } \\
\mathrm{Mu}<\mathrm{M}\end{array}$} \\
\hline & & SAP2000 (Mu) & $\begin{array}{c}\text { Response2000 } \\
(\mathrm{Mr})\end{array}$ & $\begin{array}{l}\text { SAP2000 } \\
(\mathrm{Nu})\end{array}$ & $\begin{array}{c}\text { Response2000 } \\
(\mathrm{Nr})\end{array}$ & $\begin{array}{l}\text { SAP2000 } \\
\text { (Vu) }\end{array}$ & $\begin{array}{c}\text { Response2000 } \\
(\mathrm{Vr})\end{array}$ & \\
\hline \multirow{3}{*}{ Lantai 1} & D-50 & 51,277 & 198,70 & 382,438 & 1563,40 & 59,358 & 251,70 & \multirow{3}{*}{ Aman } \\
\hline & $30 \times 50(\mathrm{~L})$ & 34,082 & 240,50 & 313,834 & 1090,30 & 155,193 & 270,90 & \\
\hline & $30 \times 50$ (D) & 99,967 & 276,60 & 334,225 & 1169,60 & 170,198 & 254,30 & \\
\hline \multirow{3}{*}{ Lantai 2} & D-50 & 57,138 & 181,40 & 186,964 & 1521,70 & 31,23 & 234,60 & \multirow{3}{*}{ Aman } \\
\hline & $30 \times 50(\mathrm{~L})$ & 19,774 & 212,10 & 157,731 & 1069,00 & 29,996 & 266,20 & \\
\hline & $30 \times 50$ (D) & 67,611 & 240,50 & 233,465 & 1090,30 & 221,645 & 270,90 & \\
\hline \multirow{3}{*}{ Lantai 3} & D-50 & 62,404 & 181,40 & 146,600 & 1521,70 & 30,878 & 234,60 & \multirow{3}{*}{ Aman } \\
\hline & $30 \times 50(\mathrm{~L})$ & 7,579 & 212,10 & 82,129 & 1069,00 & 23,208 & 266,20 & \\
\hline & 30x50 (D) & 22,231 & 240,50 & 125,441 & 1090,30 & 75,159 & 270,90 & \\
\hline
\end{tabular}

Keterangan:

D-50

30x50(L) : Kolom $30 \times 50 \mathrm{~cm}$ di posisi luar struktur gedung

30x50 (D) : Kolom $30 \times 50 \mathrm{~cm}$ di posisi dalam struktur gedung
Dari hasil analisis dapat disimpulkan bahwa elemen kolom pada lantai 1, lantai 2 dan lantai 3, diperoleh nilai momen ( $\mathrm{Mu}$ ) lebih kecil dari momen resistance ( $\mathrm{Mr}$ ), gaya aksial $(\mathrm{Nu})$ lebih kecil dari gaya aksial resistance $(\mathrm{Nr})$, dan gaya geser $(\mathrm{Vu})$ lebih kecil dari gaya geser resistance $(\mathrm{Vr})$ maka struktur kolom tersebut aman.
2. Kekuatan elemen balok.

Analisis elemen balok menggunakan Response-2000 dapat diketahui nilai momen dan gaya geser dari penampang. Dalam analisis elemen balok ini diambil 4 portal seperti pada Tabel 11. 
Tabel 11 Perbandingan Momen resistance ( $\mathrm{Mr}$ ) dengan (Mu) dan gaya geser resistance $(\mathrm{Vr})$ dengan $(\mathrm{Vu})$ Balok

\begin{tabular}{|c|c|c|c|c|c|c|c|c|c|c|}
\hline \multirow{3}{*}{$\begin{array}{l}\text { Portal/ } \\
\text { Lantai }\end{array}$} & \multirow{3}{*}{$\begin{array}{l}\text { Dimensi } \\
\text { Balok }(\mathrm{cm})\end{array}$} & \multicolumn{4}{|c|}{ Momen $(\mathrm{kN} . \mathrm{m})$} & \multicolumn{4}{|c|}{ Gaya Geser V (kN) } & \multirow{3}{*}{$\begin{array}{c}\text { Cek } \\
\mathrm{Mu}<\mathrm{Mr}\end{array}$} \\
\hline & & \multicolumn{2}{|c|}{ SAP2000 (Mu) } & \multicolumn{2}{|c|}{ Response $2000(\mathrm{Mr})$} & \multicolumn{2}{|c|}{ SAP2000 } & \multicolumn{2}{|c|}{ Response 2000} & \\
\hline & & Tumpuan & Lapangan & Tumpuan & Lapangan & Tumpuan & Lapangan & Tumpuan & Lapangan & \\
\hline \multicolumn{11}{|l|}{ Portal 4} \\
\hline Lantai 2 & $\begin{array}{l}\text { (11) T-25x50 } \\
\text { (17) T-25x50 }\end{array}$ & $\begin{array}{l}14,36 \\
24,21\end{array}$ & $\begin{array}{c}5,842 \\
12,812\end{array}$ & $\begin{array}{l}112,30 \\
136,00\end{array}$ & $\begin{array}{l}173,70 \\
213,10\end{array}$ & $\begin{array}{l}7,769 \\
18,44\end{array}$ & $\begin{array}{c}11,605 \\
17,1\end{array}$ & $\begin{array}{l}108,80 \\
206,30\end{array}$ & $\begin{array}{l}137,50 \\
273,60\end{array}$ & Aman \\
\hline Lantai 3 & $\begin{array}{l}\text { (11) T- } 25 \times 50 \\
\text { (17) T- } 25 \times 50\end{array}$ & $\begin{array}{l}17,75 \\
12,41 \\
\end{array}$ & $\begin{array}{l}6,461 \\
3,852\end{array}$ & $\begin{array}{l}112,30 \\
136,00\end{array}$ & $\begin{array}{l}173,70 \\
213,10\end{array}$ & $\begin{array}{l}23,13 \\
21,37\end{array}$ & $\begin{array}{l}29,456 \\
24,003\end{array}$ & $\begin{array}{l}108,80 \\
206,30\end{array}$ & $\begin{array}{l}137,50 \\
273,60\end{array}$ & Aman \\
\hline Dak & $\begin{array}{l}\text { (11) T- } 25 \times 50 \\
\text { (17) T- } 25 \times 50\end{array}$ & $\begin{array}{l}6,2 \\
4,7 \\
\end{array}$ & $\begin{array}{c}4,918 \\
2,99\end{array}$ & $\begin{array}{l}112,30 \\
136,00\end{array}$ & $\begin{array}{l}173,70 \\
213,10 \\
\end{array}$ & $\begin{array}{l}12,7 \\
5,34\end{array}$ & $\begin{array}{c}16,08 \\
2,36\end{array}$ & $\begin{array}{l}108,80 \\
206,30\end{array}$ & $\begin{array}{l}137,50 \\
273,60 \\
\end{array}$ & Aman \\
\hline \multicolumn{11}{|l|}{ Portal5 } \\
\hline Lantai 2 & $\begin{array}{l}\text { (17) T-25x50 } \\
\text { (31) T-30x75 }\end{array}$ & $\begin{array}{l}17,7 \\
66,69 \\
\end{array}$ & $\begin{array}{c}8,008 \\
59,696\end{array}$ & $\begin{array}{l}136,00 \\
216,70\end{array}$ & $\begin{array}{l}213,10 \\
543,30 \\
\end{array}$ & $\begin{array}{l}19,09 \\
102,3 \\
\end{array}$ & $\begin{array}{c}33,48 \\
89,848 \\
\end{array}$ & $\begin{array}{l}206,30 \\
562,10 \\
\end{array}$ & $\begin{array}{l}273,60 \\
353,50 \\
\end{array}$ & Aman \\
\hline Lantai 3 & $\begin{array}{l}\text { (17) T- } 25 \times 50 \\
\text { (37) T-30x75 }\end{array}$ & $\begin{array}{l}13,8 \\
22,8 \\
\end{array}$ & $\begin{array}{l}4,065 \\
47,07 \\
\end{array}$ & $\begin{array}{l}136,00 \\
208,40 \\
\end{array}$ & $\begin{array}{l}213,10 \\
543,30 \\
\end{array}$ & $\begin{array}{l}13,2 \\
84,7 \\
\end{array}$ & $\begin{array}{c}22,5 \\
40,77 \\
\end{array}$ & $\begin{array}{l}206,30 \\
562,10 \\
\end{array}$ & $\begin{array}{l}273,60 \\
353,50 \\
\end{array}$ & Aman \\
\hline Dak & $\begin{array}{l}\text { (17) T-25x50 } \\
\text { (15) T- } 30 \times 60\end{array}$ & $\begin{array}{l}5,9 \\
5,7 \\
\end{array}$ & $\begin{array}{c}5,111 \\
7,3\end{array}$ & $\begin{array}{l}136,00 \\
213,30\end{array}$ & $\begin{array}{l}213,10 \\
352,90 \\
\end{array}$ & $\begin{array}{l}4,16 \\
16,8 \\
\end{array}$ & $\begin{array}{l}1,451 \\
24,73 \\
\end{array}$ & $\begin{array}{l}206,30 \\
453,80 \\
\end{array}$ & $\begin{array}{l}273,60 \\
454,40 \\
\end{array}$ & Aman \\
\hline \multicolumn{11}{|l|}{ Portal 9 } \\
\hline Lantai 2 & $\begin{array}{l}\text { (31) T-30x75 } \\
\text { (31) T-30x75 }\end{array}$ & $\begin{array}{l}30 \\
57 \\
\end{array}$ & $\begin{array}{l}43,4 \\
30,6 \\
\end{array}$ & $\begin{array}{l}216,70 \\
216,70 \\
\end{array}$ & $\begin{array}{l}543,30 \\
543,30 \\
\end{array}$ & $\begin{array}{l}101 \\
36\end{array}$ & $\begin{array}{l}57,8 \\
64,2 \\
\end{array}$ & $\begin{array}{l}562,10 \\
562,10 \\
\end{array}$ & $\begin{array}{l}353,50 \\
353,50\end{array}$ & Aman \\
\hline Lantai 3 & $\begin{array}{l}\text { (37) T-30x75 } \\
\text { (37) T-30x75 }\end{array}$ & $\begin{array}{l}84,5 \\
104 \\
\end{array}$ & $\begin{array}{c}74,800 \\
98,2\end{array}$ & $\begin{array}{l}208,40 \\
208,40 \\
\end{array}$ & $\begin{array}{l}543,30 \\
543,30 \\
\end{array}$ & $\begin{array}{l}79,7 \\
80,7 \\
\end{array}$ & $\begin{array}{c}69,200 \\
73,6\end{array}$ & $\begin{array}{l}563,40 \\
563,40 \\
\end{array}$ & $\begin{array}{l}371,00 \\
371,00 \\
\end{array}$ & Aman \\
\hline $\begin{array}{l}\text { Portal 10-12 } \\
\text { Balok-Lt.3 }\end{array}$ & (37) $\mathrm{T}-30 \times 75$ & 43,2 & 71,54 & 208,40 & 543,30 & 57,3 & 57,43 & 563,40 & 371,00 & Aman \\
\hline Portal 12 & & & & & & & & & & \\
\hline Lantai 2 & $\begin{array}{l}\text { (17) T-25x50 } \\
\text { (31) T-30x75 }\end{array}$ & $\begin{array}{l}28,7 \\
105 \\
\end{array}$ & $\begin{array}{l}25,78 \\
63,71 \\
\end{array}$ & $\begin{array}{l}136,00 \\
216,70 \\
\end{array}$ & $\begin{array}{l}213,10 \\
543,30 \\
\end{array}$ & $\begin{array}{c}45,4 \\
28 \\
\end{array}$ & $\begin{array}{l}119,6 \\
103,9\end{array}$ & $\begin{array}{l}206,30 \\
562,10 \\
\end{array}$ & $\begin{array}{l}273,60 \\
353,50 \\
\end{array}$ & Aman \\
\hline Lantai3 & $\begin{array}{l}\text { (17) T- } 25 \times 50 \\
\text { (37) T- } 30 \times 75\end{array}$ & $\begin{array}{l}38,6 \\
104 \\
\end{array}$ & $\begin{array}{l}19,55 \\
58,14 \\
\end{array}$ & $\begin{array}{l}136,00 \\
208,40\end{array}$ & $\begin{array}{l}213,10 \\
543,30 \\
\end{array}$ & $\begin{array}{l}49,4 \\
93,1 \\
\end{array}$ & $\begin{array}{l}58,73 \\
86,16 \\
\end{array}$ & $\begin{array}{l}206,30 \\
563,40 \\
\end{array}$ & $\begin{array}{l}273,60 \\
371,00 \\
\end{array}$ & Aman \\
\hline $\begin{array}{l}\text { Ring } \\
\text { Balok }\end{array}$ & (7) $20 \times 30$ & 1,959 & 3,474 & 27,60 & 38,80 & 4,339 & 3,727 & 112,00 & 84,80 & Aman \\
\hline
\end{tabular}

Dari hasil analisis elemen balok dapat disimpulkan bahwa elemen balok yang diwakili oleh elemen balok pada portal 4, portal 5, portal 9, dan portal 12, diperoleh nilai momen (Mu) lebih kecil dari momen resistance (Mr), dan gaya geser $(\mathrm{Vu})$ lebih kecil dari gaya geser resistance (Vr) maka struktur balok tersebut aman.

3. Kekuatan elemen pelat lantai. Kekuatan elemen pelat lihat pada Tabel 12.

Tabel 12 Perbandingan Momen resistance (Mr) dengan Momen (Mu) Pelat Lantai

\begin{tabular}{|c|c|c|c|c|}
\hline \multirow[b]{2}{*}{ Lantai } & \multirow{2}{*}{$\begin{array}{c}\text { Dimensi } \\
\text { Pelat } \\
(\mathrm{cm})\end{array}$} & \multicolumn{2}{|c|}{ Momen (kN.m) } & \multirow{2}{*}{$\begin{array}{c}\text { Cek } \\
\mathrm{Mu}< \\
\mathrm{Mr}\end{array}$} \\
\hline & & $\begin{array}{c}\text { Manual } \\
\text { (Mu) }\end{array}$ & $\begin{array}{c}\text { Shell200 } \\
0 \text { (Mr) }\end{array}$ & \\
\hline Lantai & $t=12$ & 5,988 & 30,09 & Aman \\
\hline Lantai & $t=12$ & 7,532 & 30,09 & Aman \\
\hline
\end{tabular}

Hasil analisis elemen pelat lantai dapat disimpulkan bahwa elemen pelat lantai pada lantai 2 dan lantai 3, diperoleh nilai momen $(\mathrm{Mu})$ lebih kecil dari momen resistance (Mr), maka elemen pelat lantai tersebut aman.

4. Analisis kekuatan elemen struktur atap

Dari hasil analisis rangka batang kuda-

kuda baja, atap bangunan induk dapat diperoleh informasi bahwa konstruksi kudakuda tersebut aman karena:

- Warna biru pada rangka batang menunjukkan rasio tegangan batang tidak melebihi tegangan ijin.

- Nilai rasio tegangan yang terbesar terjadi pada batang vertikal di puncak kuda-kuda akibat kombinasi beban nomor 3 yaitu 0,347 .

\section{KESIMPULAN}

Berdasarkan hasil evaluasi yang telah dilakukan terhadap Bangunan Gedung Kantor Bupati Sumbawa, dapat disimpulkan sebagai berikut:

1. Hasil uji material beton bertulang dengan alat Schmidt Hammer Test dan Ultrasonic Pulse Velocity (UPV) Test didapat hasil kuat tekan beton pada struktur existing yaitu elemen kolom $11 \mathrm{MPa}$, elemen balok 24 MPa dan elemen pelat lantai $40 \mathrm{MPa}$.

2. Hasil perhitungan simpangan antarlantai (story drift) kinerja batas ultimit arah (U-S) dan arah (B-T) yang terjadi pada setiap lantai struktur gedung masih lebih kecil dari batas izin yang disyaratkan oleh RSNI 031726-2012. 
3. Hasil perhitungan stability ratio struktur gedung pada masing-masing arah (U-S) dan arah (B-T) pengaruh P-Delta dapat diabaikan, karena nilai stability ratio yang terjadi pada semua lantai kurang dari 0,1 sesuai ketentuan yang disyaratkan oleh RSNI 03-1726-2012.

4. Hasil perhitungan separasi gedung (building sparation) Model dengan Atap antara gedung induk dan gedung sayap struktur gedung aman terhadap tumbukan pada saat terjadinya gempa, dan untuk Model tanpa Atap defleksi maksimum total yang terjadi adalah sebesar $3,10 \mathrm{~cm}$, lebih besar dari separasi existing yaitu $1,5 \mathrm{~cm}$, (tidak memenuhi ketentuan yang disyaratkan oleh RSNI 03-1726-2012).

5. Hasil analisis elemen kolom pada lantai 1 , lanta 2 dan lantai 3, diperoleh nilai momen (Mu) lebih kecil dari momen resistance $(\mathrm{Mr})$, gaya aksial $(\mathrm{Nu})$ lebih kecil dari gaya aksial resistance $(\mathrm{Nr})$ dan gaya geser $(\mathrm{Vu})$ lebih kecil dari gaya geser resistance ( $\mathrm{Vr})$, maka struktur kolom tersebut aman.

6. Hasil analisis elemen balok yang diwakili oleh elemen balok pada portal 4, portal 5, portal 9, dan portal 12, diperoleh nilai momen (Mu) lebih kecil dari momen resistance $(\mathrm{Mr})$ dan gaya geser $(\mathrm{Vu})$ lebih kecil dari gaya geser resistance ( $\mathrm{Vr})$, maka struktur balok tersebut aman.

7. Hasil analisis elemen pelat lantai pada lantai 2 dan lantai 3, diperoleh nilai momen (Mu) lebih kecil dari momen resistance (Mr) maka elemen pelat lantai tersebut aman.

8. Hasil analisis struktur atap menggunakan software SAP 2000, rangka batang kudakuda baja pada bangunan induk adalah warna biru menunjukkan rasio tegangan yang terjadi tidak melebihi tegangan ijin, struktur atap aman.

9. Dari hasil analisis kinerja struktur gedung dan analisis kekuatan elemen struktur, tidak diperlukan perkuatan (retrofitting) terhadap elemen struktur. Pada dilatasi antara bangunan induk dan bangunan sayap harus dipastikan tidak terjadi kontak antar struktur, celah dilatasi dapat dipasang material sejenis karet agar dilatasi dapat berfungsi dengan baik.

Guna pengembangan penelitian lebih lanjut dalam hal evaluasi kinerja Gedung Kantor Bupati Sumbawa, maka disarankan beberapa hal sebagai berikut:

1. Untuk mendapatkan data uji bahan yang lebih teliti dalam evaluasi struktur gedung tersebut sedapat mungkin pengambilan data pada struktur dengan jumlah titik uji yang lebih banyak dan merata.

2. Hasil Pengujian material beton bertulang dengan alat Schmidt Hammer Test dan Ultrasonic Pulse Velocity (UPV) Test perlu dikonfirmasi dengan hasil uji material dengan alat lainnya sebagai perbandingan agar diperoleh hasil yang lebih akurat.

3. Perlu dikembangkan metode evaluasi struktur yang sesuai dengan kondisi dan peraturan standar Indonesia agar dapat menjadi acuan bagi semua pihak.

\section{DAFTAR PUSTAKA}

Anonim, 2002, Unadang-undang RI Nomor 28 Tahun 2002 , Tentang Bangunan Gedung, Jakarta.

Budiono, B., 2011, Konsep SNI Gempa 17262012, Makalah Seminar HAKI 2011.

Budiono, B. dan Supriatna, L., 2011, Studi Komparasi Desain Bangunan Tahan Gempa Dengan Menggunakan SNI 031726-2002 dan RSNI 03-1726-2012, Penerbit ITB, Bandung.

FEMA 451, 2006, NEHRP Recomended provision: Design Examples, National Institute of Building Sciences, Washington, D.C.

SNI 03-1726-2002, Standar Perencanaan Ketahanan Gempa Untuk Struktur Bangunan Gedung, Standar Nasional Indonesia, Kementerian Pekerjaan Umum.

SNI-1726-2012, Standar Perencanaan Ketahanan Gempa Untuk Struktur Bangunan Gedung, Standar Nasional Indonesia, Kementerian Pekerjaan Umum.

Suhendro, B., 2010, Analisis Dinamik Struktur, Jurusan Teknik Sipil Fakultas Teknik, UGM, Yogyakarta.

Widodo, 2001, Respons Dinamik Struktur Elastik, UII Press, Yogyakarta. 
